Lengua y Sociedad en el Mundo Hispánico

Language and Society in the Hispanic World

Editado por / Edited by

Julio Calvo Pérez (Universitat de València)

Luis Fernando Lara (E1 Colegio de México) Matthias Perl (Universität Mainz)

Armin Schwegler (University of California, Irvine)

Klaus Zimmermann (Universität Bremen)
Yolanda Congosto Martín

Elena Méndez García de Paredes (eds.)

\section{Variación linguiística y contacto de lenguas en el mundo hispánico}

In memoriam MANUEl Alvar

Vol. 27 


\title{
MODELOS IDIOMÁTICOS, CODIFICACIÓN DE USOS Y PRESCRIPTIVISMO ${ }^{1}$
}

\author{
ELENA MÉNDEZ GARCÍA DE PAREDES \\ Universidad de Sevilla
}

\begin{abstract}
Español es el suprasistema abarcador de todas las realizaciones de nuestra lengua. O dicho técnicamente: la lengua abstracta que todos aceptamos, que tiene virtualidad en la lengua literaria escrita y que ninguno habla. Es el sistema considerado fuera del individuo. Pero esta abstracción se realiza en millones de actos comunicativos (la parole) que están trabados por dos órdenes de fuerzas, las geográficas y las sociales (Alvar 1996: 236).
\end{abstract}

\section{Introducción}

A partir de $1977^{2}$, la planificación lingüística llevada a cabo por las distintas instituciones oficiales autonómicas para normalizar las llamadas lenguas "propias" ha sido objeto tratado no sólo por políticos y lingüistas (que son a quienes competen en primer lugar dichas actuaciones), sino que ha trascendido también al discurso de la información mediática, bien como hechos referidos (sobre los cuales se informa), bien como hechos comentados (con la posición ideológica que

1. Este trabajo ha sido realizado dentro del proyecto I+D "Tipología textual y oralidad: del español clásico a la actualidad", HUM2007-60410/FILO. Se inserta dentro de una serie de artículos sobre el concepto de norma en los que se analizan aspectos relacionados con la codificación del español y el reflejo que ésta ha tenido en sus usos "ejemplares". Igualmente se analizan cuestiones relativas al carácter panhispánico de las políticas lingüísticas actuales, más en consonancia con un ideal de lengua pluricéntrico, por ejemplo, en lo que respecta a nuevas relaciones y referencias de las variedades con respecto a lo codificado como estándar, así como la discusión sobre los problemas prácticos que ello puede plantear (véase Méndez García de Paredes 1999, 2008a, 2008b, 2009a, 2009b).

2. Fecha en que la Constitución Española recoge en su artículo 3. la cooficialidad del español con las otras lenguas peninsulares de las regiones consideradas históricamente bilingües y señala explícitamente que las demás variedades regionales "serán objeto de especial respeto y protección" (artículo 3.3.). 
todo comentario suele llevar aparejada), bien como hechos provocados ${ }^{3}$ (cuando, por ejemplo, es el propio medio de comunicación el que alienta discursos de reivindicación lingüística o provoca debates en torno a las lenguas, susceptibles, luego, de engrosar nuevamente y retroalimentar el discurso informativo). Este discurso mediático sobre las actuaciones lingüísticas en el ámbito de las lenguas "propias" ha repercutido consecuentemente en la conciencia lingüística de una gran masa social, generando, incluso en hablantes de zonas no bilingües, un sentimiento lingüístico sobre su propia modalidad de habla inusitado en otras épocas, de modo que se observan ahora reacciones desde dentro de la modalidad de habla local hacia la lengua estándar que tienden a calcar y a mimetizar ${ }^{4}$ las actuaciones propias de hablantes bilingües. Así, podría decirse que nada de lo que atañe a la lengua española, $o$ a sus variedades internas, $y$ a su convivencia con las otras lenguas de España les es ajeno ya a los españoles.

En estas situaciones, los filólogos y los lingüistas son convocados en calidad de "expertos en la materia" para responder a las dudas que suelen planteárseles a los profanos en estas cuestiones o para resolver posibles demandas sociales (por ejemplo, qué variedad de lengua usar en determinadas situaciones comunicativas - principalmente en los medios de comunicación orales - o si es posible o conveniente promover variedades regionales para convertirlas en estándar o no) que obligan a reflexionar sobre los aspectos teóricos (y/o metodológicos) relacionados con conceptos como los que dan título a este trabajo (o con otros, por ejemplo, los de corrección idiomática, norma lingüística, lengua estándar). Lo esperable en estas circunstancias es que la reflexión del científico, como "discurso de experto" que es, quede a salvo de orientaciones ideológicas, lo cual no es nada fácil, porque en todo lo relativo a modelos idiomáticos de una comunidad o

3. Para estos tecnicismos puede consultarse Charaudeau (2003). Como muestra de lo que se entiende con respecto a este tema por acontecimiento provocado puede verse Méndez $(1997,2003,2009 \mathrm{~b})$.

4. En un trabajo reciente, Kabatek (2006) señala el hecho de que los discursos generados sobre las lenguas, tanto en el seno de la ciencia como en otros ámbitos de la sociedad, se convierten en tradiciones metadiscursivas capaces de ser aplicadas y extendidas a otras situaciones diferentes de aquellas en las que se crearon. La historia reciente sobre la situación lingüística peninsular es buena muestra de ello. A partir del llamado período de transición, los debates sobre la articulación lengua propia / lengua común del Estado toma otra deriva y se articula como modalidad propia/lengua estándar con los efectos sociales que ello puede llevar consigo. Basta con repasar todo lo que, desde diferentes sectores, se ha escrito, por ejemplo, sobre la situación del asturiano, el extremeño, el andaluz o el murciano. La prensa puede ser un buen espejo para analizar el filtrado y reflejo social de estas cuestiones (para el caso del andaluz, véase Méndez 1997 y 2003). 
a procesos de elaboración e instrumentación de una variedad formal de la lengua no están implicados propiamente hechos intralingüísticos, sino sociales (selección de determinados usos o variedades de una lengua histórica, juicios evaluativos concomitantes, valor simbólico que suele adquirir la variedad seleccionada, por estar asociada a las características sociopolíticas, económicas y culturales del grupo de hablantes que la utiliza, etc. $)^{5}$; por eso, como ha sido señalado, los discursos que tratan sobre las lenguas de España (o el estatus de las variedades) no siempre son constatativos (no describen realidades lingüísticas) sino performativos (en cuanto que crean hechos que sirven para marcar solidaridades con respecto a la identidad local o con respecto a lo global y universal) (Kabatek 2007, Woolard 2007). Y así es como la "palabra de experto" aparece en la corriente discursiva (mediática o no) que constituyen los discursos de planificación lingüistica o los que tratan las relaciones entre la lengua estándar y las variedades dialectales del español.

En este trabajo se intentará un acercamiento descriptivo a los conceptos de modelo idiomático, codificación de usos y prescriptivismo implicados en el estatus de las variedades del español y en el comportamiento sociolingüístico de los hablantes.

\section{La denominación del modelo idiomático}

No se trata de volver aquí sobre la vieja cuestión de cómo designar a la lengua que hablamos, si castellano o español, nombres con idéntica extensión designativa, pero distinta intensión significativa que representan una visión interesada de

5. De hecho, los procesos de conformación de modelos idiomáticos de una sociedad se entienden como "parte de la serie de prácticas ideológicas por medio de las cuales se producen las creencias y actitudes de una comunidad de hablantes" (Conde Silvestre 2007: 311). Igualmente se habla de una "ideología de la estandarización" (Milroy \& Milroy 1985: 2223). Hay quienes señalan los beneficios de la convergencia hacia un modelo constituido que reduce la variación y ofrece, a cambio, garantías de estabilidad para la unidad de un idioma; mientras otros hablan de injerencia de grupos de presión elitistas, que de forma arbitraria y externa al ser de la lengua, "imponen" y "promueven al rango de estándar" una variedad como modelo supuestamente "neutro" (Conde Silvestre 2007: 312). Es decir, la existencia de un estándar siempre lleva consigo un cierto tipo de reacción social como consecuencia: por un lado, de la prescripción normativa y, por otro, de la depreciación de otras variedades de la lengua (calificadas, por referencia a él, negativamente como no-estándares o subestándares), al margen de que pueda ser calificada de "patológica" porque se conforma en "ausencia de diversidad" (Hudson 1981: 44). 
cada hablante en relación a la lengua que hablat; sino de las denominaciones que se han propuesto para referirse a esta variedad de lengua elaborada y modélica que actúa como una fuerza modeladora y tiende a igualar o nivelar los usos de los hablantes dentro de una lengua histórica, pues cada una de ellas, en cuanto formas designativas, ya son un síntoma de la orientación ideológica de los discursos. Algunas son claramente inapropiadas, otras ambiguas, otras pretendidamente neutras sin llegar a conseguir con plenitud esta neutralidad.

2.1. En primer lugar, se puede considerar la denominación de lengua oficial, pero es un nombre ambiguo e inapropiado. Es ambiguo por su polisemia, pues por una lado designa a la lengua por la que se rige la vida política y administrativa de un pueblo, esto es, la lengua en la que se redactan y promulgan las leyes que regulan la vida de un Estado7 y por otro, supone un estilo de lengua, el de la administración y el de la vida política y jurídica, que se deja traslucir en todos los textos redactados por las distintas fuentes de carácter oficial (uso que para muchos ya es lengua especial). Es inapropiado, porque el hecho de que sea la lengua del Estado no lleva aparejada su total normalización y su completa estandarización (el caso de la lengua vasca, lengua oficial en su territorio - aunque la oficialidad sea compartida - sería un ejemplo de esto). Además, sobre las lenguas oficiales pueden operar fuerzas políticas de naturaleza contraria, de forma que unas veces se promueve una determinada lengua al estatuto de oficialidad y otras veces se desplaza (el caso del español y el inglés en el Estado Libre Asociado de Puerto Rico puede ser un buen ejemplo de ello).

2.2. El nombre de lengua nacional responde a varios motivos: uno, porque su promoción y enseñanza se constituye en una empresa para cada nación; otro, porque es fruto de una planificación lingüística por parte de los estados, pero también, y sobre

6. A. Alonso ya lo señaló magistralmente: "Como la significación de una palabra no consiste exclusivamente en la designación del objeto significado, sino que incluye la perspectiva interesada con que el objeto es considerado y vivido, bien podríamos decir que, en estricto sentido, los nombres de nuestro idioma tienen significaciones distintas. Castellano y español nombran un mismo objeto con perspectivas diferentes. $Y$ aun en el correr de la historia, la visión subjetiva que acompaña a cada nombre ha ido cambiando [...] La historia espiritual de estos nombres no es más que la enredada historia de los sentimientos y de los anhelos de la fantasía y de los impulsos activos nuestros y de nuestros antepasados lingüísticos con relación al idioma común" (Alonso 1943: 142-143).

7. Según una sentencia del Tribunal Constitucional: "Es oficial una lengua, independientemente de su realidad y peso como lengua social, cuando es reconocida por los poderes públicos como medio normal de comunicación en y entre ellos y en su relación con los sujetos privados con plena validez y efectos jurídicos" (González Ollé 1995: 38). 
todo, porque cumple dos funciones complementarias (o mejor dicho, dos aspectos complementarios de la misma función), con frecuencia acompañadas de una fuerte carga emocional (que se activa cuando un conflicto real o pretendido afecta a la comunidad hablante — Gallardo 1978-): una función separadora, pues el contraste con otras comunidades de lengua diferente favorece la identidad colectiva de un "pueblo" (de ahí la lengua como hecho diferencial de los nacionalismos), y una función unificadora, o de cohesión de los hablantes, pues se entiende que anula o neutraliza las diferencias lectales propias de cada uno de ellos y fomenta su participación en asuntos de trascendencia (Gallardo 1978, Wagner 1983, Hernández Alonso 1993 y Torrejón 1993). Como es la variedad de lengua que permite la función de participación en empresas de mayor envergadura, es también la lengua a la que se traducen las aportaciones que a la vida colectiva han hecho otras naciones con lenguas diferentes, con lo que desarrolla un proceso de intelectualización y maduración expresiva. Pese a todo, tampoco este nombre es adecuado pues tiende a introducir en lo lingüístico el concepto de territorialidad que ni es una necesidad histórica, ni implica necesariamente la continuidad de una lengua en un determinado territorio (Kabatek 2007). Nación y lengua son dos realidades de distinta naturaleza que no tienen por qué recubrirse mutuamente, como lo prueba el que en una nación puedan convivir varias lenguas diferentes y el que una misma lengua sea signo de identidad colectiva de varias naciones ${ }^{8}$.

\subsection{Tampoco resultan totalmente adecuados los nombres de lengua común ${ }^{9}$} o lengua general. Es cierto que puede entenderse como común porque neutraliza los rasgos diastráticos y diatópicos y porque su elaboración la constituye como una lengua relativamente homogénea (actúa, pues, como marco de referencia de

8. Pese a ello, como señala Torrejón (1993), dentro de una lengua ampliamente extendida por el mundo, como lo es la española, las normas cultas de cada nación cumplen la función separadora de la que se ha hablado. De ahí que una correcta planificación lingüística deba promover un ideal de lengua que esté en consonancia con esas normas cultas nacionales, porque en caso contrario es dificil que ese ideal arraigue en la comunidad, pues se siente muy lejano e inalcanzable y se corre el peligro de que la comunidad desestime su cultivo (Candia 1983: 117-128).

9. Coseriu (1990: 56 y ss.) distingue como diferentes grados de abstracción la lengua común y la lengua ejemplar. Esta última, según él, se promueve como ejemplaridad porque la lengua común, que virtualmente debería ser unitaria, no escapa a los fraccionamientos diastráticos y diatópicos. Por esta razón, parece preferible pensar que la lengua ejemplar, como modelo de lengua ideal, tiende a ahormar la lengua común. Lo ejemplar es la fuerza aglutinante que se manifiesta en la abstracción lengua común. Sin embargo, el hecho de que en una lengua como el español puedan existir ejemplaridades nacionales diferentes se refleja en la lengua común que se presenta fragmentada. 
una lengua histórica), pero no siempre es común a todos los hablantes, pues su disponibilidad y acceso no son equilibrados. De ahí que su difusión y arraigo se haya sentido siempre una tarea de Estado, en el sentido de que los objetivos de la nivelación lingüística (la propiedad de urbanización) sólo se consiguen con una política lingüística reflexiva, seria, coherente, cuya acción se manifiesta formalmente en la enseñanza e informalmente en los medios de comunicación social. Con la consecución de esos objetivos, todavía hoy muy lejanos, sí serían viables y apropiados los nombres de común y general. Pero mientras todos los usuarios no accedan en igualdad de condiciones a esa lengua modelo, los nombres se vuelven opacos e imprecisos porque lo que presuntamente se califica de común es brecha para acentuar aún más las diferencias sociales. De ahí las críticas continuas a la norma lingüística y la acusación de que la lengua estándar sea elitista.

2.4. Es totalmente inapropiado el nombre de lengua correcta que suelen emplear quienes con una actitud "purista" confunden los planos lingüísticos y tienden a ver los procesos de descripción y codificación gramatical o léxica de ciertos usos formales de la lengua escrita como la "lengua toda", la lengua por antonomasia (de la cual se habla, además, como una abstracción que nadie realmente posee). Se interpreta, así, la norma codificada como una verdadera norma prescriptiva y se generan valoraciones en los hablantes que tienden a considerarla como el único modelo de corrección e, incluso, como la única realización de lengua posible. La codificación actúa en cierto sentido como un mecanismo de comprobación de los usos: si están reflejados en los tratados gramaticales se juzgan correctos, y en caso contrario, incorrectos ${ }^{10}$. Sin embargo, una lengua no puede ser nunca correcta o incorrecta, pues tal juicio no es aplicable al sistema, sino sólo al hablar, y cada hablar tiene su propia corrección, puesto que remite siempre a una cierta tradición idiomática con la que pretende corresponderse (Coseriu 1990). Por eso mismo, la existencia de un determinado modelo idiomático nunca puede servir de pauta de corrección para modos de hablar que tienen como referencia otro ideal de lengua $^{11}$. La corrección, pues, no es nunca cualidad de la lengua estándar, sus pro-

10. "Ninguna otra variedad tiene los recursos y el prestigio del estándar escrito. El hecho de que exista como un objeto descrito en los libros de gramática produce la idea de que es, de alguna manera, la lengua 'verdadera' y 'legítima', y que las otras variedades son versiones degeneradas o corruptas de ella [incluso se les niega la existencia]. Pero se trata de una realidad 'falsa', producto de una obra de ingeniería lingüística conscientemente planificada" (Romaine 1996: 109).

11. No sirve de pauta de corrección para otras normas objetivas, pero sí actúa como punto de referencia con respecto al cual se definen en lingüística las variedades lectales como marcadas diatópica, diastrática o diafásicamente (Simone 1997; Koch/Oesterreicher 2007). 
piedades son otras: bien de tipo estructural (intelectualización y estabilidad flexible), bien de tipo cultural (arraigo y urbanización) (Haugen 1974, Gallardo 1978, Wagner 1983, Hernández Alonso 1993 y Torrejón 1993).

2.5. El nombre de lengua culta hace referencia a la sedimentación y decantación de los usos lingüísticos en las situaciones formales que son propias de lo que se conoce como distancia comunicativa, pues tales usos se han fijado históricamente en los procesos de escritura. Se refiere, asimismo, a los criterios estimativos de selección que operan históricamente en la descripción y codificación de las lenguas, conjugados, en ocasiones, con algún tipo de ideal geográfico. Es la lengua de los "varones doctos", como quería Nebrija, menos diversificada en lo lectal porque viene ahormada por los modelos literarios, por la lengua escrita literaria $^{12}$. No conviene del todo este nombre, porque puede parecer demasiado unida a la idea de que la codificación tradicional de tal variedad está alejada de la lengua viva, hablada, de manera que estructuras lingüísticas propias de la inmediatez de lo oral se pueden sentir extrañas o apartadas de lo que se entiende por "culto", pese a que son normales también en estos hablantes, pues se corresponden con universales lingüísticos de la inmediatez.

2.6. El nombre de estándar, aplicado a la lengua, lengua estándar, se generalizó desde fines del siglo xviII para referirse a una variedad del inglés (standard) usada por la gente culta, y tiene la ventaja de que no está tan ideológicamente orientado como los anteriores. Además, encierra cierto sentido de normalidad sin connotaciones de corrección, ni valoraciones sobre "el bien y el mal intrínsecos" (Garvin/Mathiot 1974: 303). Se define como "la forma codificada de un idioma que es aceptada y sirve de modelo a una comunidad relativamente grande" (Ibíd. 305). Según esto, rasgo esencial es su codificación consciente y explícita, que tiende a reducir los modelos existentes y a unificarlos para permitir su intercam-

12. "El material que he utilizado es exclusivamente literario. Pocas veces he manejado testimonios orales. Este hecho hará pensar, probablemente que me alejo de la fuente viva del decir y que mi Gramática toma una orientación filológica más que lingüística. Es posible que así sea. [...] Rehúyo, por otra parte, la anotación de los hechos más aberrantes de la norma común, especialmente en la fonética y en la morfología, [...] Pero no debe perderse de vista que mi objetivo es el español común, el español cuidado que hablan las gentes cultas y universitarias de Madrid. $Y$ entre ese español hablado y literario no existe, sobre todo en nuestros días, una distancia considerable. Las diferencias son más de léxico que de gramática" (Fernández Ramírez [1951] 1985: 307-308).

"En todo caso se ha apoyado la descripción en la autoridad de escritores dominantemente peninsulares, que escribieron a finales del siglo pasado o en el siglo xIx hasta nuestros días" (Alcina/Blecua 1975:11). 
biabilidad y su utilización precisa y específica como instrumento de comunicación. Parecida, es la definición de Romaine:

Variedad altamente codificada que ha recibido el grado de desarrollo y elaboración necesario para servir a una amplia gama de funciones. El proceso de normalización convierte a una variedad en estándar fijando y regulando su ortografía, morfología, sintaxis, etc., por medio de diccionarios y gramáticas, que sirven como autoridad en la enseñanza prescriptiva de nativos y extranjeros.

La normalización no es una propiedad inherente, sino una característica adquirida, o mejor, deliberada y artificialmente impuesta. Las lenguas estándar no surgen en el transcurso de una evolución lingüística "natural" ni nacen a la existencia de repente, sino que son creadas mediante planificación consciente y deliberada (1996: 107).

No obstante, ambas definiciones tienden a subrayar más bien el punto final de un largo proceso de la conformación de los estándares, la codificación (y como consecuencia de ella, el efecto modelador y la aceptación que ejerce sobre los usos lingüísticos), y marginan el carácter histórico del proceso por el cual un determinado uso lingüístico deviene modelo idiomático y se convierte en estándar (Romaine alude a que es una construcción al margen de los procesos naturales de cambio lingüístico). Desvinculan por tanto todo este proceso de aspectos antropológicos y universales del lenguaje: por ejemplo, los que se relacionan con las circunstancias comunicativas relevantes que determinan lo que se ha descrito como el continuum concepcional oralidad / escritura(lidad), el cual se sustenta en la articulación de diferentes parámetros de carácter gradual que determinan las estrategias de verbalización de los hablantes entre los dos polos de ese continuo: el polo de la inmediatez y el polo de la distancia (Koch/Oesterreicher). Los estándares son lengua de la distancia, caracterizada por "una expresión libre de vacilaciones [estándar], léxico-semánticamente precisa y sintácticamente integrada [que] es particularmente apta para la verbalización de estados de cosas complejos" (Koch/ Oesterreicher 2007: 379), de ahí que en su conformación ejerza una fuerza estructurante la lengua escrita. Lengua que, por otro lado, es la que hasta hace poco ha permitido la fijación de los productos del hablar y su reflexión metalingüística y gramatical, esto es, el tipo de lengua que facilita la tarea de codificación.

2.7. Otro de los nombres que pueden alternar con el de estándar es el de lengua ejemplar que propone Coseriu (1990: 57-61) y que sí subraya, como se verá más adelante, el carácter histórico de conformación de tal variedad: un ideal de lengua que se constituye dentro de la lengua común y actúa por encima de ella, convirtiéndose en su norma ideal. No obstante, la diferencia con respecto a lengua 
estándar es que ésta se concibe como un modelo ideal único y homogéneo, mien tras que ejemplaridades (en el sentido que se le da en los trabajos de Coseriu), al menos en una lengua como la española, puede haber varias, que comparten grandes parcelas de vocabulario, pronunciación y sintaxis porque están constituidas dentro de la lengua común pero difieren en determinados aspectos (más notable en lo fonético y en el léxico). El nombre de lengua ejemplar aplicado al español, pero también a cualquier lengua, subraya mejor que el de lengua estándar que el ser de los modelos idiomáticos, aun estando sometidos a procesos de instrumentación y elaboración, no es tan artificial como se piensa, en tanto en cuanto que, para las lenguas particulares, ese deber ser de la lengua ejemplar tiene que corresponderse con el modo de ser habitual de una lengua, esto es, con la variación.

\section{Norma lingüística y prescriptivismo}

En el significado del término norma como término del metalenguaje científico se entrecruzan varios de los sentidos con que se emplea esta palabra en el español común (Rey 1972, Lara 1976, 1999 y 2007, Méndez García de Paredes 1999). Por un lado, el que se refiere a la idea de canon, modelo, guía, ejemplo ${ }^{13}$, que en lingüística se aviene con los conceptos norma de corrección y gramática normativa. Por otro lado, el que subraya lo que hay de común, usual, lo que es o se da como práctica acostumbrada, sentido que adquiere la palabra norma como tecnicismo introducido por Coseriu (1952). La norma consuetudinaria es "lo constante y repetido, el hábito hecho tradición idiomática", lo "normal"14, de manera que, definida como conjunto de hábitos repetidos y constantes en una comunidad idiomática, permite una descripción del SER una lengua y se presume objetivo, pues se despoja de toda connotación prescriptiva, no dice cómo DEBE SER dicha lengua.

Aclaramos, además, que no se trata de una norma en el sentido corriente, establecida o impuesta según criterios de corrección y de valoración subjetiva de lo expresado,

13. A partir de un significado básico heredado del latín 'escuadra usada por los artífices para arreglar y ajustar los maderos, piedras y otras cosas' ( $D R A E \mathrm{~s}$. v. "norma") se producen asociaciones más o menos figuradas que tienen como punto de partida "la justeza con la que deben encajar las piezas'. De ahí, 'regla sobre la manera como se debe hacer o está establecido que se haga cierta cosa', fácilmente especializable en filosofía como término đeontológico, 'regla con respecto a la que ajustar la conducta': lo que debe ser, el carácter prescriptivo.

14. Galicismo que entra en el XIX en el que está implicado el sentido de normalidad, la cualidad o condición de normal: 'dícese de lo que se halla en su natural estado' o 'de lo que es natural o regular'. 
sino de la norma que seguimos necesariamente por ser miembros de una comunidad lingüística, y no aquélla según la cual se reconoce que "hablamos bien" o de manera ejemplar, en la misma comunidad. Al comprobar la norma a la que nos referimos, se comprueba cómo se dice, y no se indica cómo se debe decir: los conceptos que, con respecto a ella, se oponen son normal y anormal, y no correcto e incorrecto (Coseriu [1952] 1973: 90).

Existe, entonces, un sentido de norma como hecho prescriptivo que se define como lo que debe ser, y otro, el de norma como hecho consuetudinario que se define como lo que es; ambos presentes tanto en la lengua común como en el metalenguaje científico. La polisemia de norma en la lengua común determina también una cierta interdependencia de los conceptos en la metalengua ${ }^{15}$ :

El hecho de que las dos normas puedan coincidir no nos interesa aquí; cabe, sin embargo, señalar que muchas veces no coinciden, dado que la "norma normal" se adelanta a la "norma correcta", es siempre anterior a su propia codificación (Ibid. 90).

Como señala Luis Fernando Lara (1976, 1999; también Rey 1972), la proximidad semántica favorece el cruce y la dependencia mutua: de un lado, las normas (preceptos) se pueden obtener por generalizaciones empiricas que se infieren de lo que es norma (costumbre); de otro, la costumbre se hace precepto cuando se codifica y una vez hecha norma prescriptiva, se adopta como elemento de juicio y establece el modelo de lo que debe ser. No debe olvidarse que la existencia de pautas (prescripciones) rectoras de comportamientos se manifiesta en el ser las cosas, en la regularidad, en el hábito ${ }^{16}$ :

De todos modos, esa norma codificable ¿no es precisamente, en cada esfera o nivel de lenguaje, el fundamento de toda normatividad? ¿No es toda norma una especie de modelo ideal? Nos parece, pues, evidente, por todos los caminos, que el estudio de las normas de ejemplaridad o de corrección o de aceptabilidad social es insoslayable en el

15. En la lengua común, se pone de manifiesto en expresiones del tipo: tener algo como norma, equivalente tanto a 'tener algo como costumbre' como a 'tenerlo como obligación'. María Moliner (1981:521) ofrece dentro de la misma acepción del vocablo (la segunda) una serie de palabras afines acostumbrado, corriente, natural, ordinario, regular; claramente separadas de criterio, ejemplo, guía, instrucción, precepto, principio..., (pero incluidas también dentro de esa acepción). La homonimia de norma, en la que confluyen sentidos procedentes de dos canales de transmisión (norma, latinismo, y normal, galicismo), se manifiesta como una adjunción de significados, como una polisemia.

16. Ésta es una de las razones por la que Lara (1999) cree que hay que evitar el término norma y sustituirlo por el de $u s o$ : se comprueba que una lengua se habla de varias formas, así que preguntarse qué lengua enseñar, es equivalente a decir qué uso de la lengua enseñar. 
vasto y complejo campo de nuestro quehacer lingüístico, teórico y aplicado. (Rosenblat 1967 [1990]: 337)

Se da, pues, la paradoja de que uno de los conceptos analizados es plenamente aceptado dentro de la teoría lingüística (el de Coseriu), porque es una norma objetiva e intralingüística; mientras que el sentido tradicional y patrimonial de "norma" se repudia por subjetiva y extralingüística. Por otro lado, como se ha visto, la codificación de la norma consuetudinaria supone replantearse su propia concepción teórica, pues hasta el llamado derecho consuetudinario tiene que ver con la fijación de la costumbre y su conversión en ley. Así, pues, como señala Alarcos (1994: 20), por muy descriptiva que se pretenda "toda gramática empieza o termina por ser normativa", sobre todo, como también se ha dicho, por el carácter "problemático" de la descripción misma:

Este énfasis desigual [que tiende a valorar ciertos dialectos y lenguas] no se debe tanto a un fallo personal de los descriptivistas como al carácter problemático de la descripción misma, que nunca puede ser una actividad neutral. En otras palabras, la descripción es siempre una forma débil de prescripción (Parakrama 1995: 3, Apud Moreno Cabrera 2000: 56 [traducción suya] $)^{17}$.

\section{La codificación de una variedad de lengua}

Una lengua histórica no conlleva un modo único de hablar "sino una 'familia" histórica de modos de hablar afines e interdependientes", de normas o tradiciones idiomáticas (Coseriu 1981: 6) ${ }^{18}$. Es un continuum estructurado de variedades (o sistemas) diatópicas, diastráticas y diafásicas, cuya coexistencia no es nunca in-

17. Se ha señalado que, pese al talante panhispánico de la RAE, la forma expositiva que adopta en la Ortografia 1999 para describir la equivalencia fónica de las grafías "c" y " $z$ " es castellanocentrista, pues siendo el seseo la pronunciación por excelencia de los hablantes de español aparece mencionada como un apéndice excepcional y visto a través de la distinción (Moreno Cabrera 2008: 136-137). Se trata de lo que se ha señalado como "la deformación del lingüista" que afecta a la jerarquía de la descripción lingüística (Simone 1997: 31).

18. Es el concepto de lengua como diasistema integrado por tradiciones idiomáticas o normas (diacrónicas, diatópicas, diastráticas y diafásicas) que se infieren de la observación de multitud de actos de habla concretos. Hay quienes, como Moreno Cabrera, denuncian el empleo ideológico con el que suele utilizarse este concepto teórico para disimular la persistencia del origen geográfico castellano en el estándar. Según él, esto ocurre frecuentemente en autores como M. Alvar o G. Salvador, que hablan de "español" como un suprasistema, como una lengua abstracta y virtual que todos aceptamos, aunque ninguno habla (Moreno Cabrera 2008: 43 y 100-103). 
conexa, pues en sincronía se establecen relaciones dentro de ese continuum (Coseriu 1981$)^{19}$. Esto hace inviable, por inabarcable, la codificación de una lengua:

Una gramática española no es una gramática del español como lengua histórica (con toda su arquitectura), lo que no sería posible, ni tampoco del español como lengua común (con sus formas regionales y sus diferentes niveles), lo que ya sería factible, pero no sin enormes dificultades, sino sólo de un modo ejemplar o considerado tal ( $\mathrm{y}$ aun esto sin toda la correspondiente variedad de estilos de lengua) (Coseriu El problema de la corrección idiomática, Manuscrito inédito. Tübingen: Archivo Coseriu (Nr. B XXXIV, 16, http://www.coseriu.de).

Habitualmente, este proceso se lleva a cabo sobre un tipo, una muestra elabora$d a$, a la que se llega por generalización y abstracción de una selección de usos provenientes de determinados registros (los formales, conformados y fijados en la lengua escrita) y de determinados grupos de hablantes (los varones doctos, entre los que se encuentra, obviamente, quien hace la descripción, el gramático o el lingüista). Se trata, pues, de una ficción gramatical, de una imagen más o menos difusa y parcial de una lengua (aunque en la descripción del lingüista se ofrece como si fuera nítida y completa). En este sentido, la codificación de un tipo de lengua puede tener un objetivo teórico y especulativo (los de la ciencia lingüística), o puede llevar un fin práctico (la enseñanza de la lengua formal y escrita a nativos y extranjeros), si bien en la historia de la codificación de las lenguas ha podido haber otros intereses. En la antigüedad el objetivo de evitar en lo posible el declive y la corrupción de la lengua (obsoleto ya en la actualidad) era de orden práctico, de donde puede explicarse la tendencia, que existe todavía en determinados hablantes, a identificar lengua codificada y corrección idiomática o, más aún, la muestra descrita como la lengua por antonomasia. Razón práctica es también abogar por la unidad de un idioma o por su expansión, objetivos actuales.

4.1. Cuando el objetivo es de carácter teórico, asistimos a lo que podríamos llamar la "paradoja de la deformación del lingüista" (Simone 1997): la lengua descrita ter-

19. Se constituye un espacio variacional en el que las relaciones siguen una dirección fija y determinada (que no admite inversión). De este modo, lo diatópico (por ejemplo el ceceo o el trueque de $l$ por $r$ ) puede funcionar como diastrático (marcado como perteneciente a un determinado estrato sociocultural), y lo diastrático, a su vez, como diafásico (el ceceo o el trueque de $l$ por $r$ pueden emplearse por hablantes de muy diversa condición social en una situación relajada e informal). Lo diatópico puede ser sometido a lo diastrático porque se trata de variaciones dentro de los grupos sociales, de manera que el territorio físico en que se habla una lengua (o una variedad) es una realidad empírica (los grupos entran en contacto en los territorios), pero no necesariamente teórica (Bell 1984, Kabatek 2007). 
mina condicionando su mirada, pues actúa como un parámetro que ordena y mide el estatus de los fenómenos lingüísticos en la variación (lo coloquial, lo dialectal, lo jergal, etc.). Sólo se puede hablar de variación cuando hay algo que varía con respecto a otra cosa que actúa como modelo de referencia. Así, el lingüista compara los dialectos y las hablas locales, sociales o coloquiales con respecto a esa abstracción que constituye la lengua por él descrita ${ }^{20}$. Ocurre, sin embargo, que los hechos de variación pueden presentarse de diferente manera en el lingüista y en el hablante: es posible que el hablante sólo conozca su variedad de habla (porque esta sea suficiente para sus actuaciones comunicativas cotidianas), y no el estándar. En este caso la variación sólo se da en el lingüista (se mezclan, entonces, los metadiscursos con la realidad ${ }^{21}$. Puede ocurrir que el hablante conozca el estándar y también una o más variedades de habla, en este caso conviene preguntarse cuál es la dirección del movimiento que se opera en él; esto es, en su competencia, cuál es su lengua ejemplar "por defecto" (Simone 1997). Hecho, quizá, determinante para el comportamiento diafásico de los hablantes ${ }^{22}$. No hay duda de que cronológicamente, para los hablantes, esa lengua por defecto en ningún caso es el estándar (por estar conformado por los procesos de escritura y, por tanto, ser lengua enseñada y aprendida $)^{23}$. Pero, aunque no preceda, sí puede, a posteriori, convertirse en su lengua de referencia (así, en los hablantes cultos); una lengua sin marcas diastráticas sobre la que proyectar su comportamiento diafásico y que para los usos de estos hablantes

20. La comparación de las variedades de una lengua con respecto a un modelo abstracto y elaborado a partir de la lengua escrita, tiende a hacer creer a los profanos en la materia ( $\mathrm{y}$ aun a veces en la forma expositiva de algunos lingüistas) que estas variedades se originan genéticamente a partir de dicho modelo que se desvirtúa y cambia por factores diversos. A esto se refiere la crítica de Penny cuando afirma: "No tiene sentido, por tanto, decir que las variedades orales empleadas en, pongamos por caso, Soria o La Mancha son 'dialectos del español', ya que esto implica una falsa relación bistórica entre cada una de estas variedades y el español" (Penny 2000: 38), en tanto que cuando se alude a ese tipo de relaciones se está pensando en "el español", como "el estándar español" y no como "el diasistema español".

21. Probablemente porque los metadiscursos están referidos a comunidades no homogéneas de hablantes en los que se supone la disponibilidad del estándar para determinados sectores.

22. Es importante porque la referencia puede ir de la ejemplaridad local al estándar o viceversa, del estándar a la variedad propia. La dirección del movimiento puede condicionar la descripción del lingüista que debe ver cómo encajar los hechos de variación.

23. En las hablas andaluzas no tiene sentido, por ejemplo, pensar que tras las formas cantaor, tocaor, madrugá, pilistra, ozú (osú, ohú, ofui) que emplean los hablantes haya necesariamente que reconstruir unas formas estándares cantador, tocador, madrugada, aspidistra, Jesús. Éstas sólo están en la mente del lingüista que tiene que encontrar sus etimologías en el proceso diacrónico fundamentado en la lengua escrita. $\mathrm{O}$ en los hablantes cultos, cuya conciencia lingüística les permite llevar a cabo el reanálisis de estas formas que han sido patrimonialmente suyas. 
elimina elementos marcados, propios de cualquiera de sus variedades dialectales (laísmos, loismos, prótasis en - ría, trueques de liquidas, simplificación de grupos cultos, aspiración de - $\mathrm{s}$, ceceos, etc.) en la mayor parte de las situaciones comunicativas. Cuando la lengua ejemplar por defecto es una variedad de habla, el movimiento se realiza hacia la ejemplaridad estándar, que debe ser elaborada cuando las situaciones comunicativas así lo requieran. A esto, por ejemplo, podrían obedecer los diferentes comportamientos de variación en los hablantes andaluces y sería interesante analizar bien esto porque es una tarea que está aún sin hacer. No parece solución la propuesta de Carbonero (2007), el cual intenta reducir dicha variabilidad a unos cuantos modelos que, según él, podrían funcionar como invariantes o prototipos para diferentes grupos de hablantes en función de su nivel sociolingüístico: el modelo septentrional, el estandarizado andaluz, el estandarizado polimórfico (combinación de los dos anteriores), el hipercorrecto (mezcla del septentrional y el vernáculo medio y bajo), el estigmatizado (vernáculo andaluz puro con la confluencia de rasgos altos, medios y bajos), el polimórfico no estandarizado (combinación del modelo septentrional bien con vernáculo bajo, bien con vernáculo medio $)^{24}$.

4.2. En el caso de la enseñanza de la lengua a nativos o extranjeros, parece fuera de lugar plantearse la pertinencia de la codificación con fines prácticos, puesto que ésta siempre se ha llevado a cabo sobre la base de la lengua escrita, la cual ya constituye en sí misma una forma de fijación y hace más fácil la reflexión metalingüistica ${ }^{25}$. A lo largo de la historia de nuestra cultura la lengua escrita y la lengua hablada han llevado una relación pendular de encuentros y desencuentros o, si se quiere, de predominio de una sobre la otra ${ }^{26}$. El descubrimiento de la escri-

24. Además de estos modelos, Carbonero habla de modelos secundarios: el estandarizado intermedio que elige para ciertas variables el modelo septentrional y para otras el estándar andaluz. Otras formas modélicas pueden deberse a otras combinaciones entre los paradigmas anteriores: el modelo hipercorrecto mitigado, el hipercorrecto y polimórfico, el estigmatizado y polimórfico. Si bien, la conclusión a toda esta variedad de comportamientos andaluces la propone el propio Carbonero: "Se entiende, pues, que la variedad de formas de pronunciación es bastante amplia y que podríamos seguir mencionando otros modelos secundarios o intermedios, con características más mitigadas o acusadas de unos u otros de los tipos básicos. En realidad, Ilegando al punto extremo podríamos decir que cada hablante en particular tiene su forma de pronunciación, o incluso varias formas (que pueden variar según la situación comunicativa en que se encuentren" (Carbonero 2007: 129).

25. "La estandarización es un proceso que tiene lugar dentro de la lengua escrita, y que es, de hecho, inconcebible en ausencia de escritura" (Penny 2000: 292).

26. Actualmente, las relaciones entre lo oral y lo escrito ya no se conciben en términos valorativos en los que una es "mejor" que otra o "más perfecta" o "más digna", ni tampoco en 
tura por una comunidad solía venir acompañado de su explotación como medio (preferido) de comunicación de la literatura, máximo exponente de la expresión idiomática ${ }^{27}$. De este modo, el prestigio que la sociedad confería a estos productos artísticos se trasladaba al modo de representación y de organización de los mensajes, hasta el punto de convertirse en referencia de los usos de una parte de la sociedad ${ }^{28}$. No hay que perder de vista que hasta hoy la historia de una lengua y de su codificación es la historia de su lengua escrita literaria, y no ha pretendido ser la de la lengua cotidiana usada por los hablantes en sus prácticas comunicativas, aunque implícitamente se hayan identificado ambas.

Toda codificación de una tradición idiomática con objetivos didácticos es de tipo normativo (vid. supra). La fijación se entiende como una verdadera norma prescriptiva porque se presenta como regular y completa; de este modo, los hablantes que la aprenden sienten esa lengua como la única y la correcta, aunque sería, quizá, interesante conseguir que no lo hicieran. La vieja idea, todavía presente en el imaginario colectivo, de que el tiempo acaba degradando una lengua por el mal uso de sus hablantes ha impedido delimitar bien los planos a los que deben referirse los conceptos de uso normativo y corrección. Como se sabe, el "purismo" lingüístico los identifica y tiende a preservar el uso normativo (lo codificado) aun a costa de otras tradiciones idiomáticas, de otras variedades no normativas. Por su parte, los detractores del estándar, para quienes las diferentes variedades de una lengua deberían estar en pie de igualdad con él, critican la actividad gramatícal (o mejor dicho, la constante instrumentación de la labor del gramático) por estar, según se dice, al servicio del mantenimiento e imposición de una variedad muy elaborada, con un origen geográfico determinado y un empleo sectorial elitista (clasista) que se intenta disimular a toda costa, "fingiéndose" que es la única y verdadera lengua para legitimar el poder social de un grupo (el que la posee) sobre otros (que no la poseen). La codificación de esta sola variedad excluye a las otras como si el resto de los usos no pudieran describirse o fueran inferiores

términos de dependencia, aunque esté comprobado que la existencia de escritura en una comunidad ahorma e influye en los modos de su oralidad, la cual se configura de forma muy distinta a la oralidad primaria de las comunidades sin escritura (Ong [1987] 1996).

27. La escritura como consignación de la palabra en el espacio da una potencialidad ilimitada al lenguaje (Ong [1987] 1996: 17).

28. La lengua escrita literaria fijó los usos ejemplares de las lenguas occidentales, los cuales se tomaron en cuenta para prescribir normas de actuación lingüística. En algunos casos, hasta la pronunciación se vio determinada por el prestigio de lo escrito, como sabemos por los intentos escolares, ya en desuso, de diferenciar la pronunciación de " $b$ " y " $v$ " o de " $s$ " y "c" o " $z$ ", de "ll" y de "y", en zonas seseantes o yeístas, por ejemplo. 
(Moreno Cabrera 2000, 2008) ${ }^{29}$. Quienes piensan así no parecen reconocer que sus planteamientos pasan por alto las prácticas comunicativas y las tradiciones discursivas en las que se decanta y a las que sirve este tipo de lengua, esto es, minimizan la importancia de los procesos de elaboración intensiva y extensiva que conlleva, y que están basados en las prácticas de escritura ${ }^{30}$. La crítica lingüística de la norma no parece entender que "las condiciones comunicativas de la distancia son irrescindibles, pues las estructuras de verbalización relacionadas con ellas presentan un potencial civilizador y emancipador irrenunciable" (Koch/ Oesterreicher 2007: 375).

\section{Los retos de la codificación del español. Lo panhispánico y el pluricentrismo $^{31}$}

Es un hecho constatado - que conviene reiterar - que los procesos de intelectualización y de elaboración intensiva decantados en una determinada variedad de lengua no están condicionados por sus especiales propiedades inherentes: nada hay en la arquitectura lingüística de una determinada variedad que de antemano la haga preferible a otra, sino que son razones diversas (demográficas o de prestigio social o de otro tipo) las que determinan ese paso de una variedad de habla a la escritura que inicia el largo proceso de estandarización o selección de variantes en contienda:

Las razones de la preferencia de la cancillería por el castellano como modalidad vernácula son diversas: por un lado, está el hecho aludido de que Fernando III fue rey de Castilla antes que rey de León y de que para entonces la cancillería castellana ya había introducido la novedad de escribir en lengua vulgar de su reino. Este avance cultural no surgía de la nada, sino que fue consecuencia del desarrollo que en ciertas diócesis y centros monásticos castellanos habia experimentado la representación gráfica de la lengua hablada desde tiempo atrás. Por otra parte, no hay que olvidar que la unión de los reinos

29. El resultado de estos planteamientos teóricos es que cuando trascienden de la refiexión crítica de los científicos a la praxis social se observa una tendencia a la desestandarización y se produce un fenómeno de mixtilingüismo (propio de la postmodernidad): las hablas locales permean la lengua de la distancia y se debilitan las fronteras propias de los ámbitos diafásicos, el registro popular se infiltra en el culto, lo coloquial en lo formal y lo hablado en lo escrito. Se origina lo que algunos han llamado "la rebelión de las masas" (Simone 2006).

30. "Quienes saben leer y escribir se convierten en una minoría poderosa que trata de imponer sus normas lingüísticas a los demás" (Romaine 1996: 112).

31. Cuando ya estaba redactado este trabajo recibi el artículo de Rivarola (2006). 
implicó el asentimiento de la nobleza y de la iglesia de León a la autoridad del rey castellano. Pero, sobre todo, el castellano fue la lengua preferida para las prácticas jurídicas y administrativas concernientes al conjunto del señorío castellano-leonés porque ya desde años atrás, desde mediados del siglo xil al menos, Castilla era el reino de más peso demográfico, de mayor extensión territorial y con una economía más pujante [...] Gracias a la práctica cancilleresca alfonsí, durante treinta años largos el castellano fue diseminando a lo largo y ancho del reino en infinidad de documentos que de facto lo proponían como modelo de lengua escrita por encima de las demás modalidades lingüísticas del reino. La percepción del nítido contraste existente entre las vacilaciones lingüísticas de los diplomas de Fernando III y la coherente seguridad de la colección documental de su hijo explica que desde antiguo se atribuyera, no sin razón, al rey Sabio la responsabilidad de la iniciativa (Fernández Ordóñez 2004: 384-385)

Esta larga cita puede servir para ilustrar el comienzo del ser de los idiomas que pasan a la escritura y se desarrollan vinculados a determinadas tradiciones discursivas, de manera que, aun estando sometidos a mecanismos conscientes de instrumentación y elaboración para hacer estas lenguas relativamente estables y permanentes necesitan tener arraigo social y aceptación en la comunidad idiomática, por ello deben estar en consonancia con lo que es el modo de ser habitual de una lengua y deben integrar la variación. Así, lo que se ha descrito como "historia del español" es la historia de un tipo de español, el escrito, la historia de un estándar, y como se ve por la historia de la lengua este estándar también ha estado sometido a cambio por la coexistencia de variantes propias de una comunidad no homogénea y por el hecho de que continuamente se den tensiones entre la lengua escrita y la lengua hablada ${ }^{32}$.

Entre las deformaciones de los lingüistas está, ya se ha dicho, la forma expositiva que puede adoptar la codificación y que, según se señala, es inherente a la presentación de los estándares. En el caso del español es lo que se ha denominado "ideología del universalismo lingüístico" tantas veces denunciado (en un principio por Montes Giraldo 1980, y modernamente por Del Valle/Stheeman 2004, Del Valle 2007, Moreno Cabrera 2008):

Este pretendido universalismo de la lengua literaria culta ha marcado su huella en la gramática tradicional y en los estudios lingüísticos y filológicos. Así, de la gramática de las "lenguas" clásicas, fundadas evidentemente sobre el dialecto literario, a la gra-

32. La lengua escrita actúa sobre las lenguas como una capa de bielo que impide ver el fluir y el dinamismo de la lengua histórica, hasta el punto de que sólo bemos sido capaces de observar el cambio en las lenguas cuando éste se termina reflejando en la lengua escrita. 
mática de las lenguas modernas y aun a la lingüística con las leyes fonéticas sin excepción, el estructuralismo con su concepción del sistema rígido y único y el transformacionalismo con su confianza en el hablante ideal, se ha mantenido la ficción de que la descripción de una parte de un sistema lingüístico, así sea una parte muy importante, es una descripción válida del conjunto total (Montes Giraldo 1980: 240).

En cuanto a partir de normas consuetudinarias de un dialecto dado en un lugar y época dados se extrae una norma que se trata de imponer a todo el complejo lingüístico como leyes válidas de la "lengua", no de un dialecto particular. No importa que este dialecto no sea estrictamente el de un lugar concreto, sino una mezcla especial de la norma consuetudinaria real de un dialecto territorial con el dialecto literario basado en aquél. [...] Esta concepción de la normatividad en la lengua hace crisis y comienza a imponerse una normatividad que ya no es la exclusiva del dialecto otrora central y dominante (Montes Giraldo 1980: 252-253).

Si bien, el denunciado efecto perturbador de la norma codificada no sólo es producto de la presentación expositiva que hasta ahora se ha venido realizando, pues ha tenido su fundamento también en un cierto fatalismo con que en época de crisis se percibió el futuro del español. La independencia de las naciones americanas a comienzos del siglo $\mathrm{xI}$, que supuso la fragmentación de la unidad de la corona española en varios Estados mayores y menores de consecuencias politicas inmediatas, afectó también a las actitudes lingüísticas de los hablantes de los nuevos países americanos $^{33}$. Se produjeron tendencias lingüísticas disgregadoras que implicaban una consciente hostilidad hacia España, y las continuas guerras entre naciones vecinas (entre Chile, Perú y Bolivia o entre Chile y Argentina) supusieron una alarma para muchos eruditos de uno y otro lado del Atlántico, temerosos de que se cumpliera para el español la misma fragmentación que se había dado en el latín y que tiempo atrás se había reflejado en la conocida frase de Puigblanch:

Los españoles americanos si dan todo el valor que dar se debe a la uniformidad del lenguaje en ambos hemisferios, han de hacer el sacrificio de atenerse, como a centro de unidad, al de Castilla, que le dio el ser y el nombre (Apud Rosenblat [1969] 1990: 236) ${ }^{34}$.

33. Tras la independencia, las nuevas Repúblicas se concibieron como Estados nacionales según el modelo europeo y pensaron en definirse en oposición tanto respecto de España como respecto de los vecinos inmediatos. Y así, "junto a la administración, la escuela y el ejército propio pertenece a las instancias de identificación del Estado nacional también la lengua propia. Entonces hablar la lengua de la antigua potencia colonial pudo sentirse como un déficit de emancipación, lo que llevó al intento de seguir conscientemente caminos particulares" (Eberenz 1995: 48). En relación con este tema, puede consultarse Eberenz (1992) y Guitarte (1991), y en este mismo volumen M. Guzmán.

34. Semejante postura opera en algunos académicos. Son famosas las palabras de Cotarelo y Mori en las que se defiende la tutela de España y particularmente Castilla en el idioma: 
El monocentrismo lingüístico de base castellana se iba afianzando como un medio de evitar la tan temida fragmentación:

¿Cuál será la norma a que todos hayamos de sujetarnos? Ya que la razón no lo pidiera, la necesidad nos forzaría a tomar por dechado de nuestra lengua a la de Castilla, donde nació, y, llevando su nombre, creció y se ilustró con el cultivo de eminentísimos escritores, envidia de las naciones extrañas y encanto de todo el mundo; tipo único reconocido entre los pueblos civilizados, a que debe atenerse quien desee ser entendido y estimado entre ellos (Cuervo 1954: 6 ) $^{35}$.

El propio Bello, autor de la primera Gramática "destinada al uso de los hablantes americanos", alerta en el "Prólogo" sobre la posibilidad de que los distintos hábitos contaminados por estructuras foráneas conviertan el idioma en "una multitud de dialectos irregulares, licenciosos y bárbaros; embriones de idiomas futuros, que durante una larga elaboración reproducirian en América lo que fue la Europa en el tenebroso período de la corrupción del latín":

No se crea que recomendando la conservación del castellano sea mi ánimo tachar de vicioso y espurio todo lo que es peculiar de los americanos: Hay locuciones castizas que en la Península pasan hoy por anticuadas y que subsisten tradicionalmente en Hispanoamérica ¿por qué proscribirlas? Si según la práctica general de los americanos es más analógica la conjugación de algún verbo, ¿por qué razón hemos de preferir la que caprichosamente haya prevalecido en Castilla? Si de raíces castellanas hemos formado vocablos nuevos, según los procederes ordinarios de derivación que el castellano reconoce, y de que se ha servido y se sirve continuamente para aumentar su caudal, ¿qué motivos hay para que nos avergoncemos de usarlos? Chile y Venezuela tienen tanto derecho como Aragón y Andalucía para que se toleren sus accidentales divergencias, cuando las patrocina la costumbre uniforme y auténtica de la gente educada (Bello [1847]1988: 160) $)^{36}$.

"Unidad que debe ser formulada por España, no porque nosotros hablemos actualmente mejor que los americanos, sino porque en España está el tesoro, la mina, la cantera que conserva para el idioma los elementos primarios de firmeza indestructible [...]; en España está nuestra vastísima y antigua literatura; a España pertenecen Cervantes y Lope [...]; en España está el pueblo castellano, que retiene en sus viejas aldeas voces y giros anteriores al descubrimiento de América. Y ¿qué mejor abolengo pueden desear los que al fin y al cabo, son nuestro hijos?" (Fries 1989: 171).

35. No obstante: "Cuando los españoles conservan fielmente el tipo tradicional, su autoridad es la razón misma; cuando los americanos lo conservamos y los españoles se apartan de él, bien podemos llamarlos al orden y no mudar nuestros usos. Si el beneficio es común, común ha de ser el esfuerzo" (Cuervo 1954: 6).

36. "Parecerá algunas veces que se han acumulado profusamente los ejemplos; pero sólo se ha hecho cuando se trataba de oponer la práctica de escritores acreditados a novedades 
Disipados estos temores, se observa desde hace décadas una tendencia a dar cabida a la tradición idiomática de las distintas naciones que hablan español para que la norma lingüística no sea monocéntrica, sino pluricéntrica:

Yo estoy sincerísimamente convencido de que toda acción rectora del futuro de nuestra lengua tiene que hacerse con absoluto respeto a las variedades nacionales tal como las usan los hablantes cultos [...] Creo, pues, que deben respetarse las variedades nacionales, que en el estado actual de la lengua no dificultan (o en el peor de los casos, no dificultan gravemente) la comunicación idiomática (Alonso 1964: 261).

De manera que a una realidad lingüística pluricéntrica le corresponda también una codificación de este tipo (aunque sea difícil una total simetría y pueda estudiarse algún tipo de jerarquización, Oesterreicher 2002, 2006a, 2006b, Lebsanft 2007). Sólo queda, pues, integrar el concepto de pluricentrismo en la codificación de la lengua dentro de una política lingüística de carácter panhispánico. La primera piedra de este nuevo edificio de codificación lingüística del español ha sido el Diccionario panhispánico de dudas (2005), empresa llevada a cabo por la Real Academia Española y la Asociación de Academias de la Lengua Española. Y en proceso de elaboración está una Gramática normativa también de carácter panhispánico, pues como la propia RAE afirma:

Se consideran plenamente legítimos los diferentes usos de las regiones lingüísticas, con la única condición de que estén generalizados entre los hablantes cultos de su área y no supongar una ruptura del sistema en su conjunto, esto es, que ponga en peligro su unidad (www.rae.es).

No obstante, pese a los nuevos planteamientos, el concepto de poli- o pluricentrismo no está exento de problemas si lo contemplamos en el ámbito de una codificación con intereses normativos (pero también cuando son simplemente descriptivos), pues a la codificación de una realidad pluricéntrica no puede exigírsele precisión ni absoluto rigor, sería una quimera inalcanzable. ¿Cuántos centros deben reconocerse y en función de qué parámetros? ¿Qué papel van a jugar el peso económico, los factores demográficos o de otro tipo? ¿Se van a tener en cuenta también otros centros dentro del propio español europeo? ¿A qué usos lingüísticos y tradiciones discursivas se va a atender para la codificación: a los usos de la distancia (ahormados por la lengua escrita), a los de la inmediatez coloquial, a

viciosas, o de discutir puntos controvertidos, o de explicar ciertos procederes de la lengua a que creía no haberse prestado atención hasta ahora" (Bello [1847] 1988: 158-159). 
ambos $^{37}$ ?, en este caso, ¿qué papel van a jugar las otras variedades del español? No menos interesante será observar si cambia la actitud de ciertos hablantes hacia la norma (y si se despoja de sus connotaciones negativas) y qué repercusión tendrán esos nuevos centros irradiadores de norma lingüística en la lengua de los medios de comunicación o en la conformación de un español neutro (otro estándar no europeo) que se ponga al servicio de la industria mediática ${ }^{38}$.

\section{Referencias bibliográficas}

Alarcos Llorach, Emilio (1994): Gramática de la lengua española. Madrid: EspasaCalpe.

Alcina, Juan/Blecua, José Manuel (1975): Gramática española. Barcelona: Ariel.

Alonso, Amado (1943): Castellano, español, idioma nacional. Buenos Aires: Losada.

Alonso, Dámaso (1964): "Para evitar la diversificación de nuestra lengua", en: Presente y futuro de la lengua española, 2. Madrid: OFINES, 259-268.

Alvar, Manuel (1996): "Andaluz", en: Alvar, Manuel (dir.): Manual de dialectología hispánica. Barcelona: Ariel, 233-258.

BeuL, Alan (1984): "Language style as audience desing", en: Language in Society, 13, 145-205.

Bélo, Andrés ([1847] 1988): Gramática de la lengua castellana. Destinada al uso de los americanos. Con las notas de Rufino José Cuervo. Estudio y edición de R. Trujillo. Madrid: Arco Libros.

CANDIA, Luis (1983): "Sentido de una gramática normativa en una planificación lingüística", en: RLA, 21, 117-128.

Carbonero Cano, Pedro (2007): "Formas de pronunciación en Andalucía: modelos de referencia y evaluación sociolingüística", en: Sociolingüistica andaluza 15, 121-132.

Charaudeau, Patrik (2003): El discurso de la información. La construcción del espejo social. Barcelona: Gedisa.

CONDE Silvestre, Juan Camilo (2007): Sociolingüística histórica. Madrid: Gredos.

Coseru, Eugenio ([1952] 1973): "Sistema, norma y habla", en: Teoria del lenguaje y lingüistica general, 3." ed. Madrid: Gredos.

— (1981): 'Los conceptos de 'dialecto', 'nivel' y 'estilo de lengua' y el sentido propio de la dialectología", en: Lingüistica Española Actual, 3, 1-32.

- (1990): "El español de América y la unidad del idioma", en: I Simposio de Filología Iberoamericana. Zaragoza: Libros Pórtico, 43-75.

37. ¿Hasta qué punto el modelo de espacio variacional, articulado gracias al continuzm concepcional inmediatez-distancia comunicativa (oralidad/escrituralidad) de Koch/Oesterreicher (2007) puede vertebrar y guiar esta tarea de codificación policéntrica de la norma lingüística del español?

38. Véase en este mismo volumen el trabajo de E. Bravo. 
Cuervo, Rufino José (1954): Apuntaciones criticas sobre el lenguaje bogotano, en: Obras completas. Bogotá: Instituto Caro y Cuervo.

Del VAl.Le, José (2007): "La RAE y el español total. ¿Esfera pública o comunidad discursiva?", en: Del Valle, J. (ed.): La lengua, ¿patria comin? Ideas e ideología del español, Madrid/Frankfurt a.M.: Iberoamericana/Vervuert, 81-96.

Del Valle, José/Stheeman, Gabriel (eds.) (2004): La batalla del idioma. La intelectualidad hispánica ante la lengua. Mađrid/Frankfurt a.M.: Iberoamericana/Vervuert.

EBEREnz, Rolf (1992): "Spanish: Sprache und Gesetzgebung. Lengua y legislación", en: Holtus, Günter et al. (eds.): Lexikon der Romanistischen Linguistik. Tübingen: Max Niemeyer, VI, 1, 368-378.

- (1995): "Norm und regionale Standards des Spanischen in Europa und Amerika", en: Müller, Oskar et al. (eds.): Sprachnormen und Sprachnormenwandel in gegenwärtigen europäischen Sprachen. Beiträge zur gleichnamigen Fachkonferenz November 1994 am Fachbereich Sprach- und Literaturwissenschaften der Universität Rostock. Rostock: Universität, 47-58.

FERNÁNDEZ Ordóñez, Inés (2004): “Alfonso X el Sabio en la historia del español”, en: Cano Aguilar, Rafael (coord.): Historia de la lengua española. Barcelona: Ariel, 381-422.

FERnÁNDEz Ramírez, Salvador ([1951] 1985): Gramática española. Madrid: Arco Libros.

Fries, Dagmar (1989): La Real Academia ante el uso de la lengua (1713-1973). Madrid: SGEL.

Gallardo, Andrés (1978): "Hacia una teoría del idioma estándar", en: Revista de Lingüística Teórica y Aplicada, 16, 85-119.

GARVIN, Paul L. (1993): "A conceptual framework for the study of language standardization", en: International Journal of Sociology of Language, 100/101, 37-54.

Garvin, Paul/Mathiot, Madeleine (1974): "La Urbanización del idioma guaraní. Problema de lengua y cultura", en: Garvin, Paul/Lastra, Yolanda (eds.): Antología de etnolingüistica y sociolingülstica. México: UNAM, 302-335.

GONZÁLEZ-OLLÉ, Fernando (1995): "El largo camino hacia la oficialidad del español en España", en: La lengua española, hoy. Madrid: Fundación Juan March, 39-61.

GuItARTE, Guillermo (1991): "Del español de España al español de veinte naciones: La integración de América al concepto de lengua española", en: $A C I E A 3,1,65-86$.

Haugen, Einar (1974): "Lingüística y planificación idiomática", en: Garvin, Paul L./Lastra, Yolanda (eds.): Antologia de estudios de etnolingüistica y sociolingülstica. México: UNAM, 278-302.

Hernández Alonso, César (1993): "El concepto de norma lingüística en Nebrija: pervivencia y superación", en: Anuario de Lietras, XXXI, 183-204.

Hudson, Richard A. (1981): La sociolingiústica. Barcelona: Anagrama.

KABATEK, Johannes (2006): "Requisitos para ser lengua: el caso del asturiano y de otras modalidades lingüísticas de España", en: Castillo, Mónica/Kabatek, Johannes (eds.), Las lenguas de España. Politica lingüística, sociología del lenguaje e ideología desde la transición hasta la actualidad. Madrid/Frankfurt a. M. Iberoamericana/Vervuert, 141-158.

- (2007): "Dos Españas, dos normalidades: visiones bipolares sobre la situación lingüistica en la España Actual", en: Estudios reunidos en homenaje a Manfred Tietz. Madrid/Frankfurt a. M.: Iberoamericana/Vervuert, 803-816. 
Koch, Peter/ Oesterreicher, Wulf (2007): Lengua hablada en la Romania: español, francés, italiano. Madrid: Gredos [Trad. A. López Serena de Gesprochene Sprache in der Romania: Französich, Italienisch, Spanisch. Tübingen: Niemeyer, 1990].

LARA, Luis Fernando (1976): El concepto de norma en lingüistica. México: El Colegio de México.

- (1999): "Normas Lingüísticas: pluralidad y jerarquía", en: $L E A, 71,13-20$.

- (2007): "Por una reconstrucción de la idea de la lengua española", en: Del Valle, José (ed.): La lengua, ¿patria común? Madrid/Frankfurt a. M.: Iberoamericana/Vervuert: 163-181.

LEBSANFT, Franz (2007): "Norma pluricéntrica del español y Academias de la Lengua", en: Laferl, Christopher F./Pöll, Bernhard: Amerika und die Norm. Tübingen: Max Niemeyer Verlag, 227-246.

MÉndez García de Paredes, Elena (1997): "Reivindicación de las hablas andaluzas en la prensa regional durante la transición", en: Cano Aguilar, Rafael (coord.): Las hablas andaluzas. Número monográfico de Demófilo. Revista de Cultura Tradicional de Andalucia, 22, 155-181.

— (1999): "La norma idiomática del español: visión histórica", en: Philologia Hispalensis, 13, 109-132.

- (2003): "El andaluz en la prensa. (Actitudes lingüísticas: 1980-1981)", en: Narbona, Antonio (ed.): El español hablado en Andalucia. II Jornadas sobre el Habla Andaluza. Estepa 2002. 139-174. Estepa: Ayuntamiento de Estepa.

- (2008a): "Modelos idiomáticos y prescriptivismo. El caso del andaluz", en: Martín Rojo, Luisa (ed.): Actas del $8{ }^{\circ}$ Congreso de Lingüistica General. El valor de la diversidad (meta)lingüistica. Madrid: Universidad Autónoma de Madrid (formato electrónico).

- (2008b): "Norma pluricéntrica, normalización lingüística y planificación de variedades. El andaluz", en: Actas del XV Congreso de la Asociación de Lingüistica y Filología de América Latina. Montevideo (formato electrónico).

- (2009a): "Pluricentrismo y panhispanismo. A propósito del Diccionario panhispánico de dudas", en: De Maeseneer, Rita, et al:: El hispanismo omnipresente. Homenaje a Robert Verdonk. Antwerpen: UPO, 223-238.

- (2009b): "La proyección social de la identidad lingüística de Andalucía. Medios de comunicación, enseñanza y política lingüística”, en: Narbona Jiménez, Antonio (coord.): La identidad lingüística de Andalucia. Sevilla: Centro de Estudios Andaluces/Consejería de la Presidencia, 213-319.

Mrroy, James/ Milroy, Lesley (1985): Authority in Language: Investigating Language Prescription and Stardardisation. London: Routledge.

Moliner, María (1981): Diccionario de uso del español. Madrid: Gredos.

Montes Giraldo, José Joaquín (1980): "Lengua, dialecto y norma", en: Thesaurus, 35, 2, 37-257.

Moreno Cabrera, Juan Carlos (2000): La dignidad e igualdad de las lenguas. Crítica de la discriminación lingüistica. Madrid: Alianza Editorial.

- (2008): El nacionalismo lingüístico. Una ideologia destructiva. Barcelona: Península.

Oesterreicher, Wulf (2002): "El español, lengua pluricéntrica: perspectivas y límites de una autoafirmación lingüística nacional en Hispanoamérica. El caso mexicano", en: Lexis $26, \mathrm{n}^{\circ} 2,275-304$. 
- (2006a): "El pluricentrismo del español", en: De Bustos Tovar, José J./Girón Alconchel, José L. (eds.): Actas del VI Congreso Internacional de Historia de La Lengua Española, vol. 3. Madrid: Arco Libros, 3079-3087.

— (2006b): "La historicidad del lenguaje. Variación, diversidad y cambio lingüístico", en:

De Bustos Tovar, José/Girón Alconchel, José L. (eds.), Actas del VI Congreso Internacional de Historia de la Lengua Española, vol. 1. Madrid: Arco Libros, 137-158.

ONG, Walter ([1987]1996): Oralidad y escritura. México: Fondo de Cultura Económica.

PARANKRAMA, Arjona (1995): De-hegemonizing Language Standard: learning from (post) colonial Englishes about 'English'. London: Macmillan.

PENNY, Ralph (2000): Variación y cambio en español. Madrid: Gredos.

Real Academia Española (1999): Ortografía de la lengua española. Edición revisada por las Academias de la Lengua Española. Madrid: Espasa-Calpe.

- (22001): Diccionario de la lengua española. Madrid: Espasa-Calpe.

Real Academia Española/ Asociación de Academias de la Lengua Española (2005): Diccionario panhispánico de dudas. Madrid: Santillana.

REY, Alain (1972): "Usages, jugements et prescriptions linguistiques", en: Lagane, R./ Pinchon, J. (eds.): La norme (Langue Française, 16). Paris: Larousse, 4-28.

Romarne, Suzanne (1996): El lenguaje en la sociedad. Una introducción a la sociolingüistica. Barcelona: Ariel.

RoSEnBlat, Ángel ([1967]1990): "El criterio de corrección en lingüistica: unidad o pluralidad de normas en el castellano de España y América", en: Estudios sobre el español de América, vol. 3. Caracas: Monte Ávila Editores, 311-337.

RIVAROLA, José Luis (2006): "El español en el siglo xxi: los desafios del pluricentrismo", en: Boletin Hispánico Helvético 8, 97-109.

Simone, Raffaelle (1997): “Cual es la lengua de default en un ambiente de variación?", en: Narbona, Antonio/Ropero, Miguel (eds.): Actas del Congreso del Habla Andalu$z a$. Sevilla: Universidad de Sevilla, 29-41.

- (2006): "Idiomas locales y nacionales: dinámica y fenómenos nuevos", en: Narbona, Antonio (ed.): Diversidad y homogeneidad del andaluz, 3. Jornadas sobre el Habla Andaluza. Estepa: Ayuntamiento de Estepa, 33-51.

TORREJón, Alfredo (1993): Andrés Bello y la lengua culta. La estandarización del castellano en América en el siglo XIX. Boulder, CO: Society of Spanish and Spanish-American Studies.

W AGNer Claudio A. (1983): "La lengua formal, lengua ejemplar", en: Revista de Lingüística Teórica y Aplicada, 21, 129-136.

WOOLARD, Kathryn A. (2007): "La autoridad lingüística del español y las ideologías de la autenticidad”, en: Del Valle, José (ed.): La lengua, ipatria común"' Ideas e ideología del español. Madrid/Frankfurt a. M. Iberoamericana/Vervuert, 129-141. 